\title{
DEFORMATION AND DAMAGE MECHANISMS IN INCONEL 718 SUPERALLOY
}

\author{
Sreeramesh Kalluri ${ }^{1}$, K. Bhanu Sankara Rao ${ }^{2}$, Gary R. Halford ${ }^{3}$, and Michael A. McGaw ${ }^{3}$ \\ ${ }^{1}$ NYMA, Inc. \\ NASA Lewis Research Center \\ Cleveland, Ohio 44135 \\ ${ }^{2}$ National Research Council - NASA Research Associate \\ NASA Lewis Research Center \\ Cleveland, Ohio 44135 \\ ${ }^{3}$ NASA Lewis Research Center \\ Cleveland, Ohio 44135
}

\begin{abstract}
The deformation and damage mechanisms in wrought, double-aged, Inconel 718 superalloy (AMS 5663D) tested under monotonic tensile strains of $2 \%$ and $10 \%$, fully-reversed fatigue, and tensile strain $(2 \%$ or $10 \%)$ followed by fully-reversed fatigue conditions were investigated by examining the microstructures of representative specimens. All tests were conducted in air at room temperature. The specimens were sectioned and examined by transmission electron microscopy to reveal typical microstructures as well as the active deformation and damage mechanisms. Specific mechanistic features addressed include the type of slip, interaction of dislocations with $\gamma^{\prime \prime}$, $\gamma^{\prime}$ and the carbides (precipitated during solidification and the subsequent heat treatment received by the superalloy), twinning, and microcracking. In all cases the microstructure of the as-received superalloy is employed as the reference to establish the nature and distribution of the secondary phases before the superalloy is subjected to different types of mechanical loading. Results of the investigation and comparisons of the mechanisms of deformation and damage observed under monotonic tensile strain, fully-reversed fatigue, and tensile strain followed by fully-reversed fatigue in Inconel 718 superalloy are reported.
\end{abstract}

\footnotetext{
Superalloys 718, 625, 706 and Various Derivatives Edited by E.A. Loria

The Minerals, Metals \& Materials Society, 1994
} 


\section{Introduction}

The nickel-base superalloy, Inconel 718 is a high-strength, high-ductility material with excellent fabrication characteristics. Its response to age hardening is sluggish and this property enables it to be welded and anncaled with no spontaneous hardening. Due to these attractive properties, Inconel 718 has been extensively used as a structural material in the aerospace industry for a variety of applications such as, gas turbine engine disks, blades, and shafts (1), large structural castings (2), and powerhead components in the Space Shuttle Main Engine (3). In view of the importance of Inconel 718, detailed investigations on different aspects of the physical metallurgy of this alloy have been conducted by various researchers (4-9).

The major intermetallic phases known to precipitate in Inconel 718 are the metastable $\gamma^{\prime}$ and $\gamma^{\prime \prime}$ and the equilibrium $\delta$ phase (4-9). The $\gamma^{\prime}\left[\mathrm{Ni}_{3}(\mathrm{Al}, \mathrm{Ti})\right]$ is a coherent face-centered cubic phase $\left(\mathrm{L1}_{2}\right.$ structure) with a volume fraction of approximately $4 \%$ (4-6). The primary strengthening phase $\gamma^{\prime \prime}$, which precipitates coherently as ellipsoidal, disc-shaped particles on $\{100\}$ planes of the fcc matrix (4-7), is based on the composition, $\mathrm{Ni}_{3} \mathrm{Nb}$ and has an ordered body-centered tetragonal $\left(\mathrm{DO}_{22}\right)$ structure. The $\gamma^{\prime \prime}$ has three variants and a volume fraction of about 15-20\%. The orthorhombic $\delta$ preferentially nucleates at the grain boundaries and grows into plates along $\{111\}$ planes in the matrix $(7,8)$ with the composition, $\mathrm{Ni}_{3} \mathrm{Nb}$. The occurrence of Laves, primary $\mathrm{MC}$ carbides $(\mathrm{Nb}$ or $\mathrm{Ti})$ and $\mathrm{TiN}$ phases has been reported in Inconel $718(8)$.

In spite of wide ranges of applications, only a limited number of investigations have been conducted on the mechanisms associated with the tensile and cyclic deformation behaviors of this alloy $(5,6,10-12)$. In this paper, the room temperature deformation and damage mechanisms in double-aged, wrought Inconel 718 (designed to give optimum properties) are reported for conditions of monotonic tensile strain, fully-reversed fatigue, and monotonic tensile strain followed by fully-reversed fatigue. The substructural changes in Inconel 718 at room temperature under monotonic and cyclic loading conditions are characterized and compared with those published in the literature $(5,6,10-12)$.

\section{Material and Experimental Details}

\section{Composition, Heat Treatment, and Sample Preparation for Microstructure}

The wrought Inconel 718 superalloy, manufactured to AMS 5663D, was obtained in the form of $31.8 \mathrm{~mm}$ dia. bars. Composition of the superalloy in wt. pct. is as follows: $0.002 \mathrm{~S} ; 0.004 \mathrm{~B} ; 0.006$ $\mathrm{P} ; 0.034 \mathrm{C} ; 0.05 \mathrm{Cu} ; 0.07 \mathrm{Si} ; 0.12 \mathrm{Mn} ; 0.39 \mathrm{Co} ; 0.57 \mathrm{Al} ; 0.95 \mathrm{Ti} ; 2.87 \mathrm{Mo} ; 5.19 \mathrm{Nb}+\mathrm{Ta} ; 17.52 \mathrm{Cr}$; $53.58 \mathrm{Ni}$; balance $\mathrm{Fe}$. The material was heat treated by the manufacturer as follows: Solution annealing at $1227 \mathrm{~K}$ for $1 \mathrm{~h}$ and water quenching + Ageing at $991 \mathrm{~K}$ for $8 \mathrm{~h}$ and furnace cooling to $894 \mathrm{~K}+$ Ageing at $894 \mathrm{~K}$ for $10 \mathrm{~h}$. Sample for optical microscopy was etched electrolytically using a solution consisting of $5 \mathrm{ml} \mathrm{H}_{2} \mathrm{SO}_{4}, 8 \mathrm{gm} \mathrm{CrO}$, and $85 \mathrm{ml} \mathrm{H}_{3} \mathrm{PO}_{4}$ and a potential of $4 \mathrm{~V}(0.5$ A) for nearly $30 \mathrm{sec} \mathrm{(13).} \mathrm{Samples} \mathrm{for} \mathrm{transmission} \mathrm{electron} \mathrm{microscopic} \mathrm{observations} \mathrm{were} \mathrm{taken}$ from the gauge sections of monotonically strained and fatigued specimens. These samples were mechanically thinned to $150 \mu \mathrm{m}$ followed by electrolytic thinning in a bath containing $20 \%$ perchloric acid and $80 \%$ methanol at a potential of $22 \mathrm{~V}$ and a temperature below $235 \mathrm{~K}$. The samples were examined in a transmission electron microscope (TEM) operating at $120 \mathrm{keV}$.

\section{Experimental Details}

Solid, uniform gauge section, specimens with a diameter of $6.25 \mathrm{~mm}$ were machined from the wrought bars of Inconel 718 superalloy. These specimens were tested at room temperature, in 
laboratory air, in a servohydraulic fatigue testing system. Strains in the uniform gauge sections of the specimens were measured with a $12.7 \mathrm{~mm}$ gauge length extensometer. Three types of experiments were conducted on the Inconel 718 specimens. First, monotonic tensile strains of $2 \%$ or $10 \%$ were imposed on the specimens under stroke-control with limits imposed on the axial strains. Next, fully-reversed, fatigue tests were conducted to failure under total axial strain-control on as-received specimens as well as specimens previously subjected to monotonic tensile strains. The test matrix and the test conditions are shown in Table I. Failure in fatigue tests was defined as separation of the specimen into two pieces.

Table I Test Matrix and Testing Conditions

\begin{tabular}{ccc}
$\begin{array}{c}\text { Monotonic Tensile Strain } \\
\text { Tests, } \varepsilon_{\mathrm{t}}\end{array}$ & $\begin{array}{c}\text { Fully-Reversed Fatigue } \\
\text { Tests, } \Delta \varepsilon_{\mathrm{t}}\end{array}$ & $\begin{array}{c}\text { Fully-Reversed Fatigue Tests on } \\
\text { Specimens Subjected to } \\
\text { Monotonic Tensile Strain, } \varepsilon_{\mathrm{t}}: \Delta \varepsilon_{\mathrm{t}}\end{array}$ \\
\hline 0.02 & 0.008 & $0.02: 0.02$ \\
0.10 & 0.02 & $0.10: 0.008$ \\
--- & & $0.10: 0.02$ \\
\hline
\end{tabular}

\section{Results}

\section{As-Received Microstructure and Tensile Properties}

The alloy contained equiaxed grains with an average linear intercept grain size of $10 \mu \mathrm{m}$ (Fig. 1). This fine grain size is a consequence of the lower solutioning temperature adopted. The doubleage heat treatment resulted in high yield and ultimate tensile strengths at room temperature. The average room temperature tensile properties of the as-received material are as follows: i) $0.2 \%$ offset yield strength: $1140 \mathrm{MPa}$, ii) ultimate tensile strength: $1410 \mathrm{MPa}$, and iii) percent reduction in area: 43.3 .

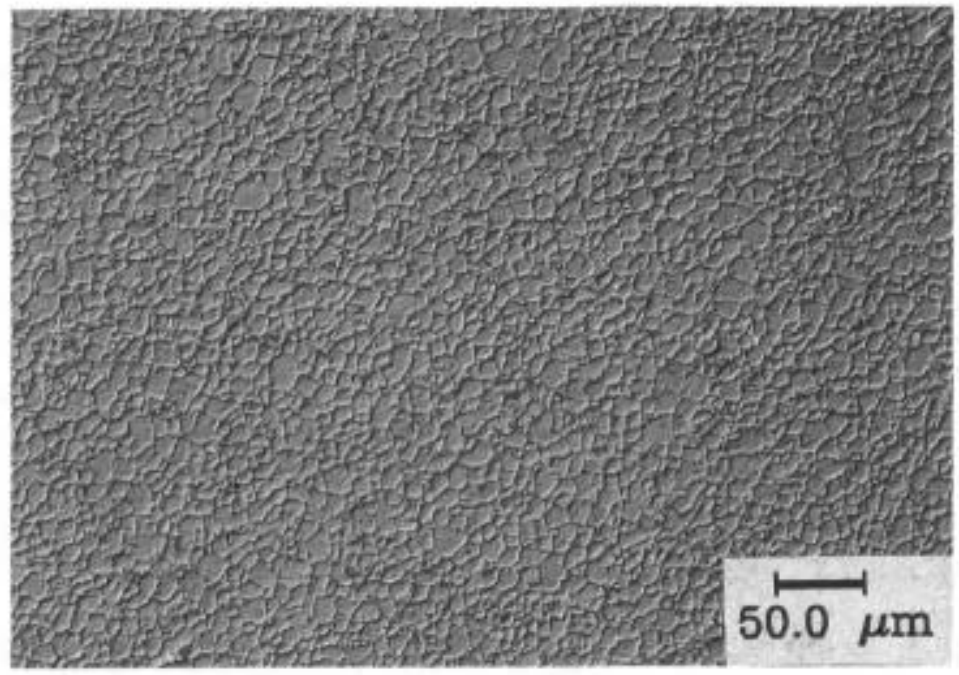

Figure 1 - Optical microstructure of the as-received Inconel 718 superalloy depicting fine grain size 
No clearly discernable precipitates could be resolved using optical microscopy. Therefore, transmission electron microscopy was used to reveal the phases and image them (Fig. 2). At the end of the double ageing treatment, the microstructure consisted of homogeneously distributed $\gamma^{\prime \prime}$ phase in the intragranular regions. Bright field TEM micrograph presented in Fig. 2a clearly shows $\gamma^{\prime \prime}$ particles and the associated coherency strain fields surrounding these particles. The discshaped $\gamma^{\prime \prime}$ particles are about $20 \mathrm{~nm}$ in diameter and $5 \mathrm{~nm}$ in thickness. These observed dimensions for $\gamma^{\prime \prime}$ are in agreement with those reported by other investigators for Inconel 718 (4, 5 , 14). Prior austenite grain boundaries were found decorated with either NbC (Figs. $2 \mathrm{~b}$ or $2 \mathrm{c}$ ) or equilibrium $\delta$-phase (Fig. 2d). Zones free from $\gamma^{\prime \prime}$ particles, however, were not seen around these grain boundaries. The $\delta$ precipitates appeared like needles whereas the carbides showed plate morphology with continuous network on some of the boundaries. A needle-shaped phase, probably either Laves (8) or intragranular $\delta(14)$, was also noticed in the as-received Inconel 718 superalloy (Fig. 2e).

\section{Cyclic Stress Response}

The evolution of stress range with the number of cycles in the fully-reversed fatigue tests is shown in Fig. 3. Inconel 718 cyclically softened at both strain ranges after a small amount of hardening during the initial cycles. The degree and rate of cyclic softening was higher for the $2 \%$ strain range fatigue test compared to the $0.8 \%$ strain range test. The variation of stress range with the number of cycles for the fatigue tests on tensile pre-strained specimens is shown in Fig. 4. In computing the stress values for the tensile pre-strained specimens during the fatigue portions of the tests, the reductions in the cross-sections of the specimens due to the monotonic tensile strains were properly taken into consideration. Even in the case of monotonically strained specimens, Inconel 718 cyclically softened during the fatigue.

At a strain range of $2 \%$ during fatigue, the specimen subjected to $10 \%$ tensile pre-strain exhibited a higher stress range than the specimens subjected to $2 \%$ tensile pre-strain and no tensile prestrain. This result is not unexpected because the material is hardened by the $10 \%$ monotonic tensile strain imposed prior to fatigue testing. Comparison of Figs. 3 and 4 clearly shows that at a strain range of $0.8 \%$, during fatigue, the stress range of the specimen subjected to $10 \%$ monotonic tensile strain is lower than that from the specimen with no monotonic strain. This result, which is unexpected and can not be explained by the hardening associated with monotonic tensile strain, will be discussed in detail later.

\section{Fatigue Lives}

At a strain range of $2 \%$, monotonic tensile straining did not have a significant effect on the subsequent fatigue life of Inconel 718 at room temperature, with the $2 \%$ tensile pre-strained specimen yielding nearly the same life as the specimen with no pre-strain and the $10 \%$ tensile pre-strained specimen yielding slightly lower life than the specimen with no pre-strain (Figs. 3 and 4). However, at a strain range of $0.8 \%$, fatigue life of the specimen subjected to $10 \%$ tensile pre-strain was lower by nearly a factor of five compared to the life of the specimen with no prestrain. This reduction in life is due to the non-linear accumulation of fatigue damage in Inconel 718. The mechanisms leading to this behavior will be discussed subsequently.

\section{Deformation and Damage Mechanisms}

Monotonic Tensile Strain. In order to study the post tensile deformation dislocation structures produced in the as-received alloy, samples deformed to 2 and $10 \%$ tensile strains were examined. In both cases, predominantly planar dislocation arrangements were observed (Fig. 5a). A large 


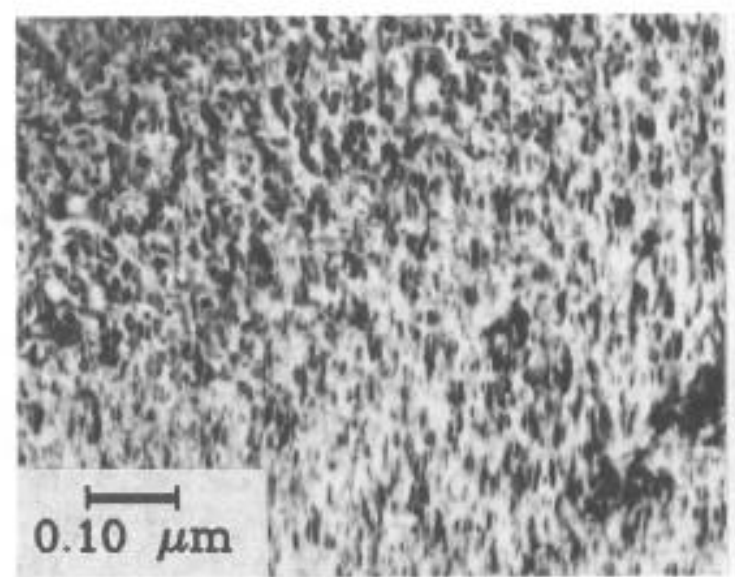

(a) Bright field image of intragranular $\gamma^{\prime \prime}$

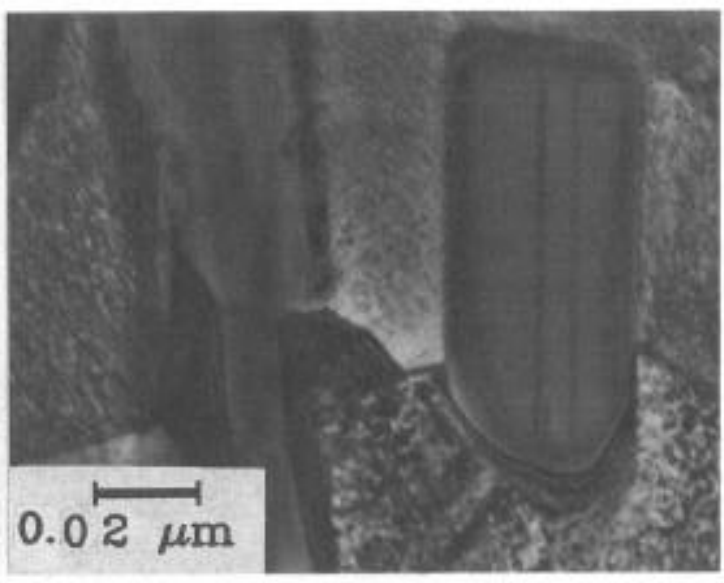

(b) Niobium carbide on the grain boundary

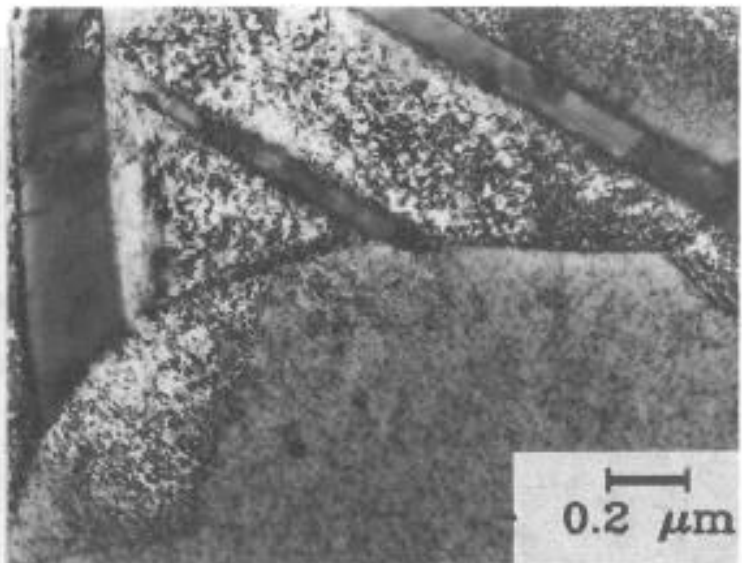

(d) Needle shaped precipitates of 8-phase on a grain boundary (c) Continuous network of Niobium-rich carbides on prior austenite grain boundary

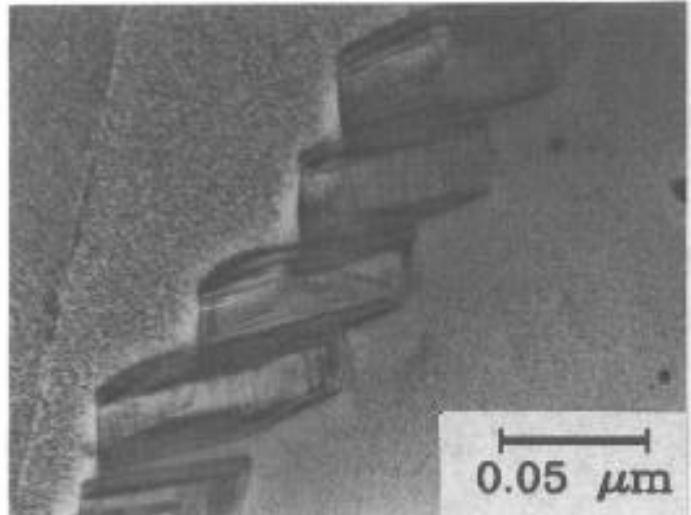

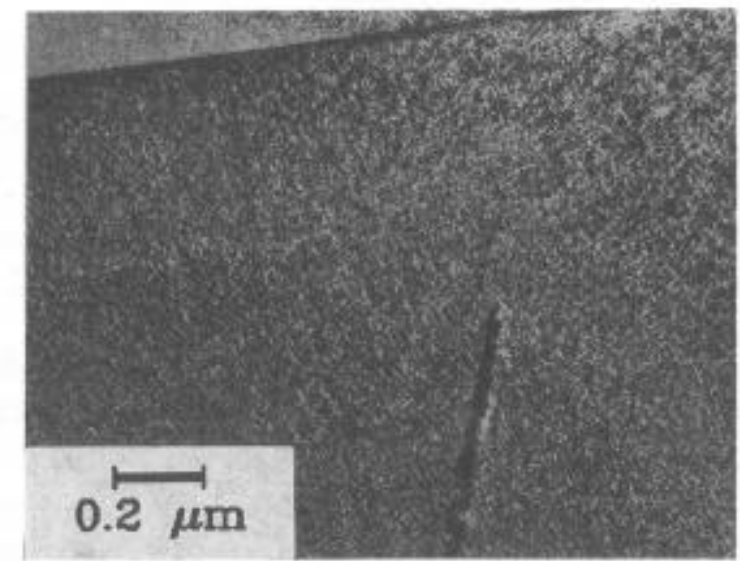

(c) Needle phase in the intragranular region

Figure 2 - Observed phases in the as-received Inconel 718 superalloy 


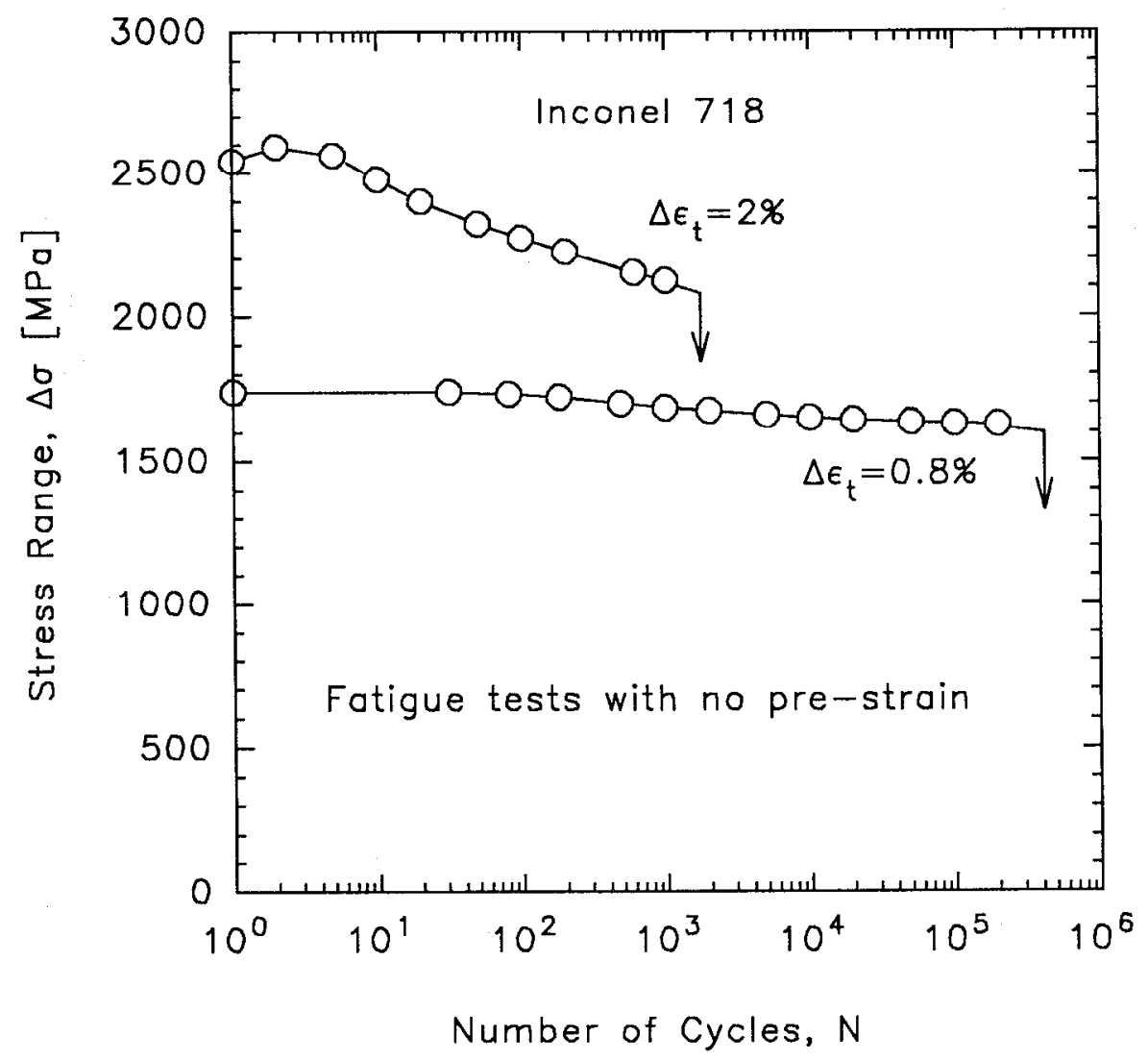

Figure 3 - Evolution of cyclic stress range in fully-reversed fatigue tests

number of dislocation pairs were noticed in samples subjected to $2 \%$ monotonic tensile deformation and these were generally associated with $\gamma^{\prime \prime}$ particles (Fig. 5b). Oblak et al. (5) and Chaturvedi and Han (6) also observed pairs of dislocations in monotonically strained Inconel 718. Presence of dislocation pairs is an evidence of shearing of ordered particles $\left(\gamma^{\prime \prime}\right)$ by glide dislocations (6). At $10 \%$ monotonic tensile strain, deformation continued in planar arrays with a higher density of planar slip bands and narrower band spacing (Fig $5 \mathrm{c}$ and $5 \mathrm{~d}$ ) compared to $2 \%$ tensile strain. Slip bands remained diffused probably as a consequence of the occurrence of cross slip within the bands.

Fully-Reversed Strain-Controlled Fatigue. Co-planar slip, dislocation pairs (evidence of $\boldsymbol{\gamma}^{\prime \prime}$ shearing), and the pile-up of dislocations near grain boundaries were observed in the specimen fatigued at a strain range of $0.8 \%$ (Figs. $6 \mathrm{a}$ and $6 \mathrm{~b}$ ). Continuation of a well-defined slip band into an adjacent twin across the boundary was also noticed in the same specimen (Fig. $6 \mathrm{c}$ ). In Inconel 718 at room temperature under fatigue, channelization of deformation seems to occur in planar slip bands after $\gamma^{\prime \prime}$ particles are sheared during the initial stages of the cycling. It is surmised that with cycling $\gamma^{\prime \prime}$ particles are successively sheared in the slip band, in the first few cycles, with an associated reduction in their size up to a point where they can no longer offer any resistance to the passage of dislocations in the slip band. Once the shearing of $\gamma^{\prime \prime}$ occurs, the trailing 


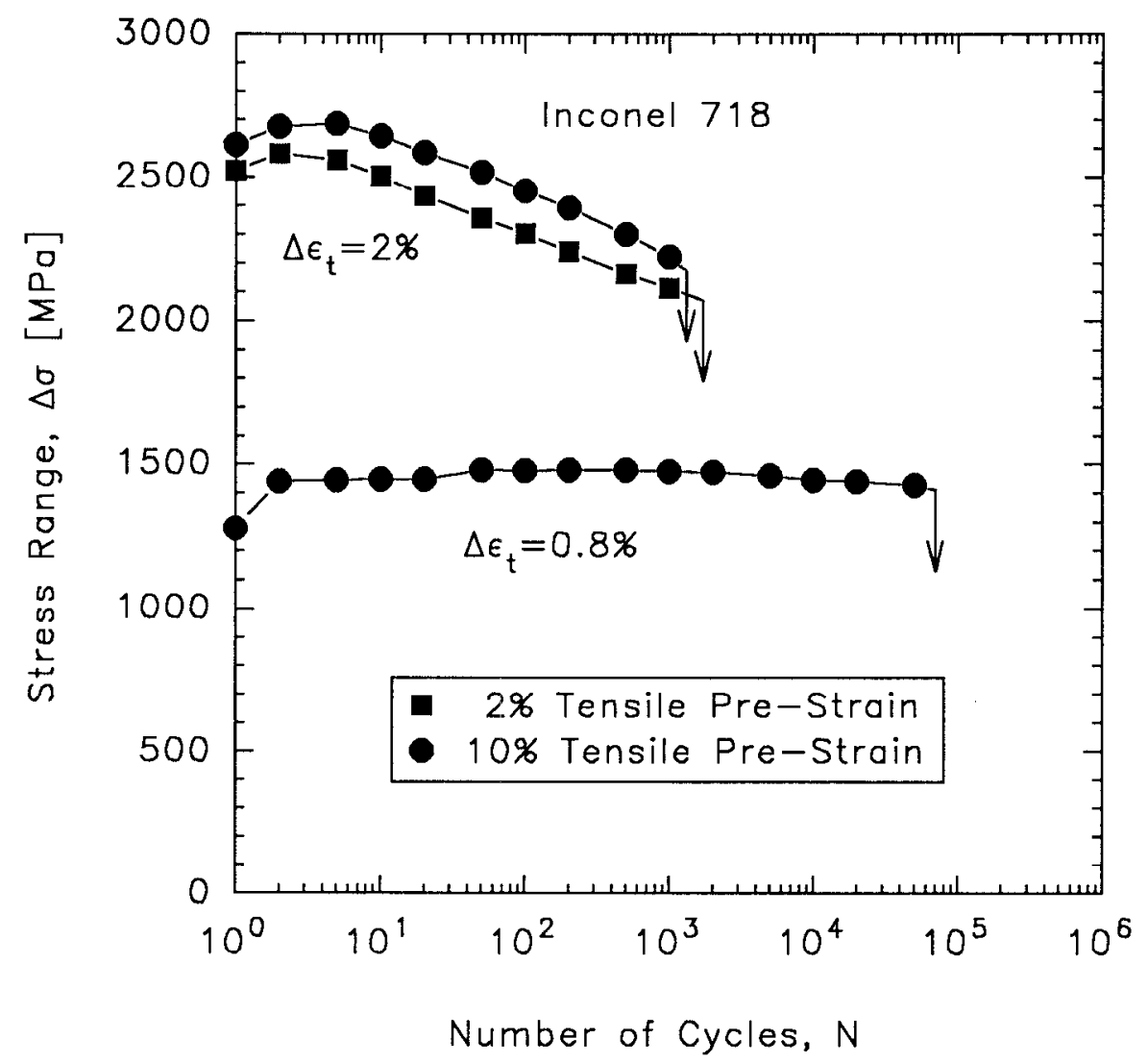

Figure 4 - Evolution of cyclic stress range in fatigue tests with tensile pre-strains

dislocations in the slip band would not encounter any ordered $\gamma^{\prime \prime}$ and this phenomenon would lead to the planar arrangement of dislocations in the slip band as depicted in Figs. 6a and 6c. The "mechanical scrambling" of the precipitates in the slip bands seems to be the mechanism behind the observed cyclic softcning in Inconel 718 (Fig. 3). In the fatigue sample tested at a strain range of $0.8 \%$, some of the deformation bands were virtually devoid of $\gamma^{\prime \prime}$ (Fig. 6d). It must also be mentioned that tilting of the TEM foils failed to reveal any sort of precipitates within these deformation bands. Several others have also observed planar slip and precipitate-free deformation bands in Inconcl 718 fatigucd at room temperature (10-12).

At a strain range of $2 \%$, in addition to the features observed at $0.8 \%$ strain range, a small amount of microtwinning was observed (Fig. 6e). The number (or density) of planar deformation bands was larger at $2 \%$ strain range compared to $0.8 \%$ strain range. Micro-twinning was reported by Fournier and Pineau (11) in Inconel 718 tested at room temperature in fatigue. At both strain ranges fatigue crack propagation occurred in a transgranular manner.

Monotonic Tensile Strain Followed by Fatigue. In the specimen tested at a strain range of $2 \%$ after a prior tensile deformation of $2 \%$, closely spaced planar slip bands with dislocationdislocation interactions within the bands were observed (Fig. 7a). The spacing between the slip bands was smaller compared to the $2 \%$ monotonically strained sample indicating that additional 


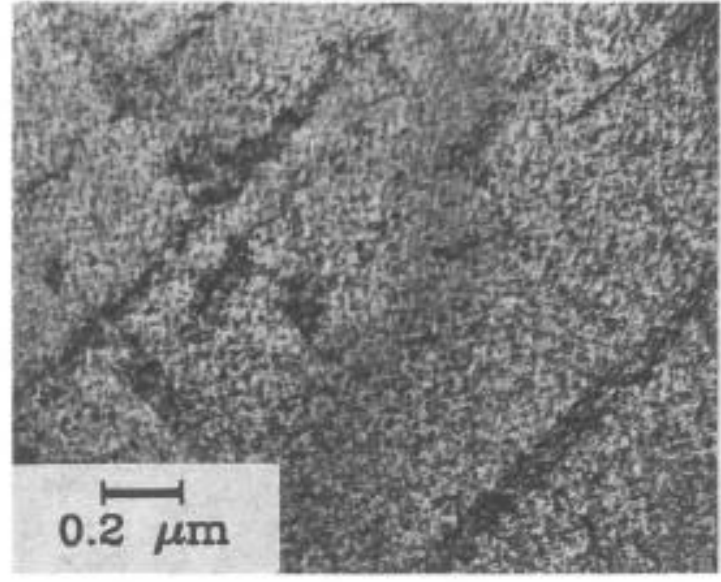

(a) Deformation in multiple planar arrays, $\varepsilon_{\mathrm{t}}=2 \%$

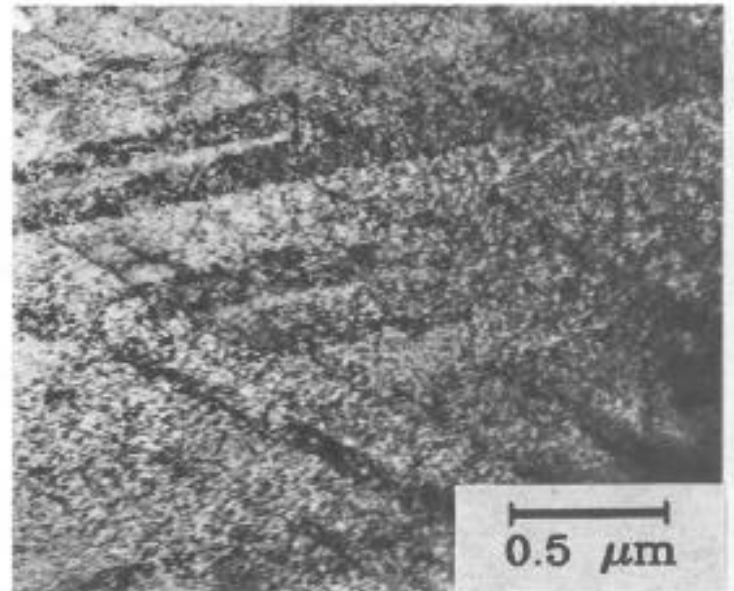

(c) High density of planar slip bands, $\varepsilon_{\mathrm{t}}=10 \%$

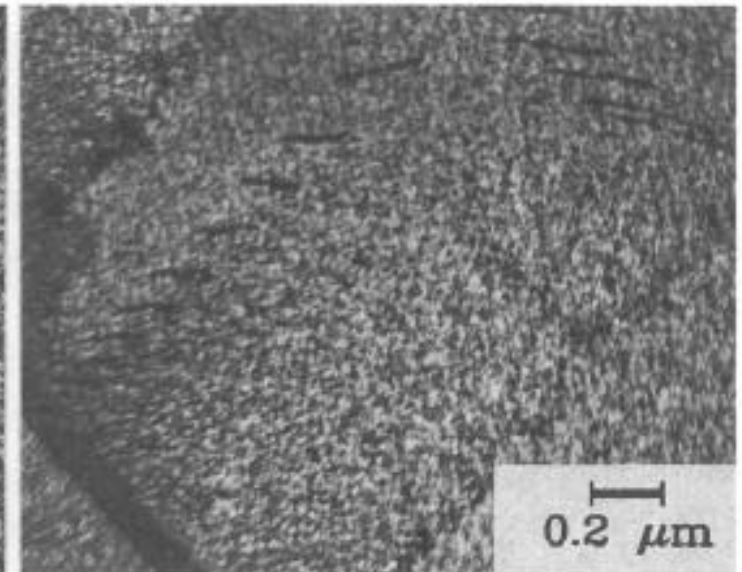

(b) Dislocations and dislocation pairs in planar slip bands, $\varepsilon_{1}=2 \%$

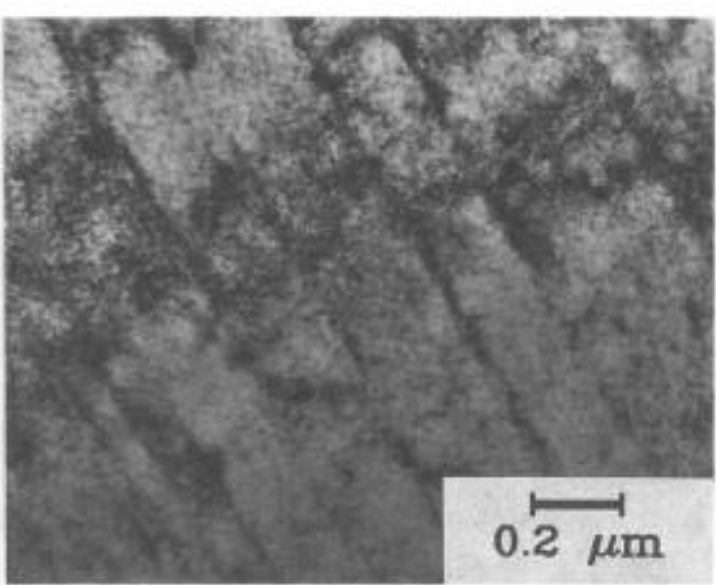

(d) Multiple diffused slip bands, $\varepsilon_{\mathrm{t}}=10 \%$

Figure 5 - Deformation substucture in monotonically strained Inconel 718

slip bands were activated during the subsequent fatigue testing at $2 \%$ strain range. Deformation induced precipitate-free channels, similar to those observed in fatigue tested samples without any tensile pre-strain, were also noticed (Fig. 7b). However, surrounding these channels very fine spherical precipitates of $\gamma^{\prime}$ were present. This observation gives an indication that in addition to the shearing of primary strengthening phase $\gamma^{N}$, the shearing of $\gamma^{\prime}$ is also occurring in this alloy.

Average slip band spacing in the specimen tested under fatigue at a strain range of $2 \%$ after a monotonic strain of $10 \%$ (Fig. 8a) is wider than that in the specimen tested in fatigue at the same strain range with a $2 \%$ tensile pre-strain (compare Figs. $7 \mathrm{a}$ and $8 \mathrm{a}$ ). This indicates that 


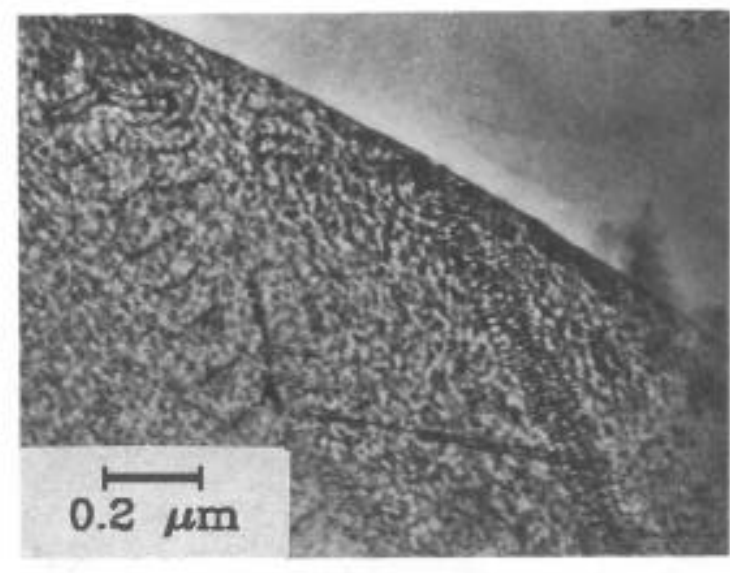

(a) Slip band, dislocation pairs, and pile-up at a grain boundary, $\Delta \varepsilon_{\mathrm{t}}=0.8 \%$

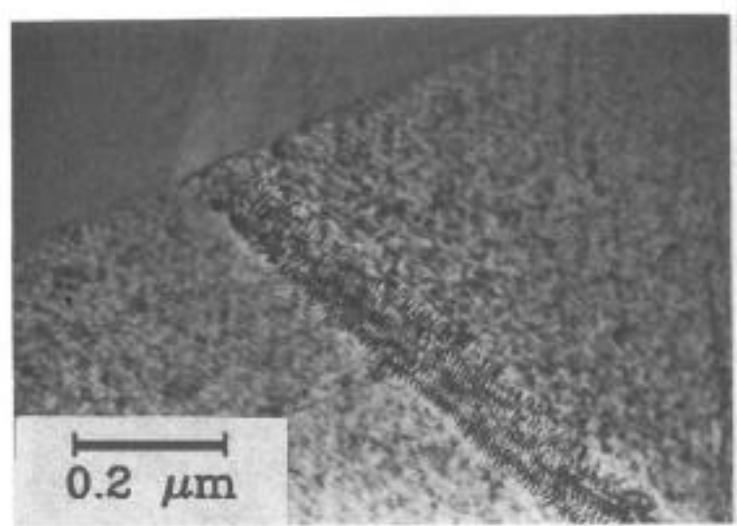

(c) Continuation of planar slip band into a twin, $\Delta \varepsilon_{\mathrm{t}}=0.8 \%$

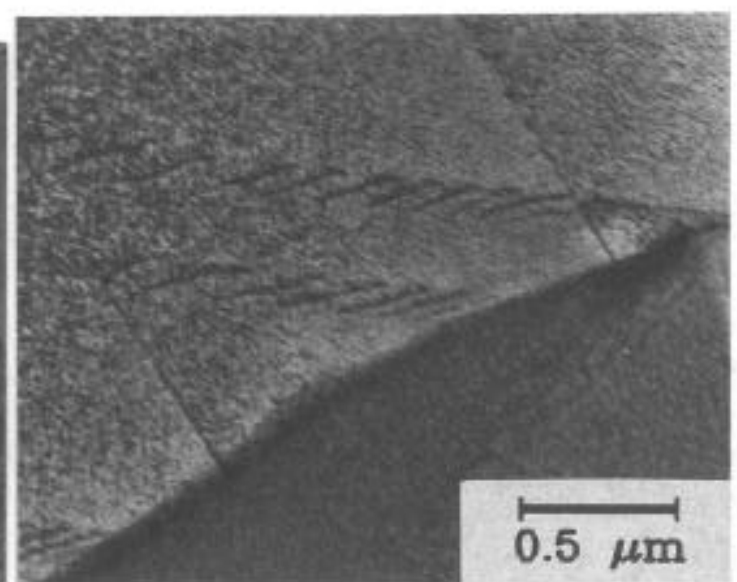

(b) Co-planar slip and dislocation pile-up, $\Delta \varepsilon_{\mathrm{t}}=0.8 \%$

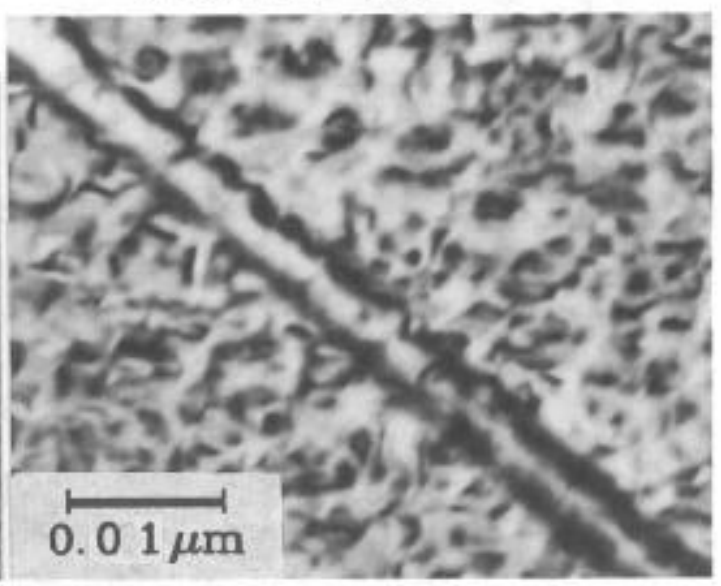

(d) Precipitate-free deformation band, $\Delta \varepsilon_{\mathrm{t}}=0.8 \%$

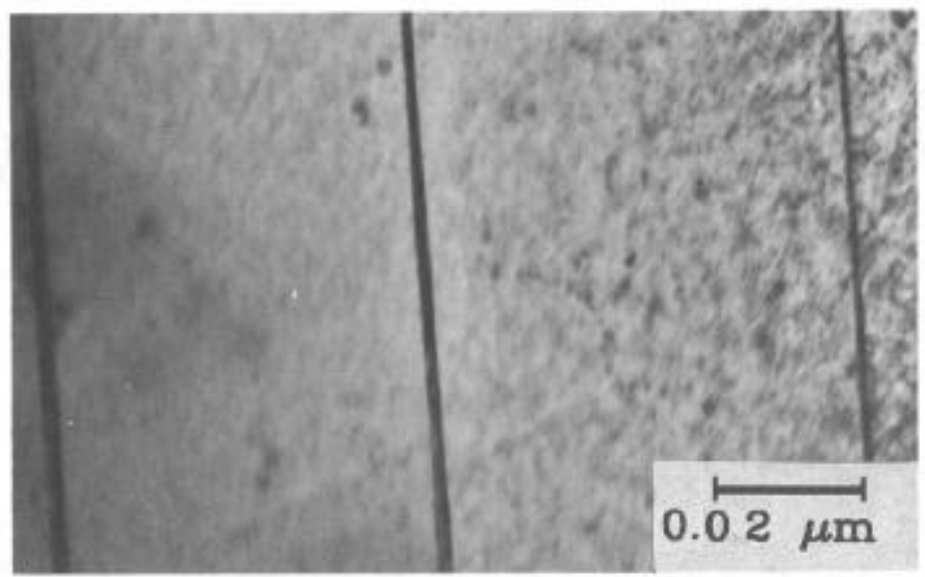

(e) Deformation induced microtwins, $\Delta \varepsilon_{\mathrm{t}}=2 \%$

Figure 6 -Substructure in Inconel 718 tested under fully-reversed fatigue 


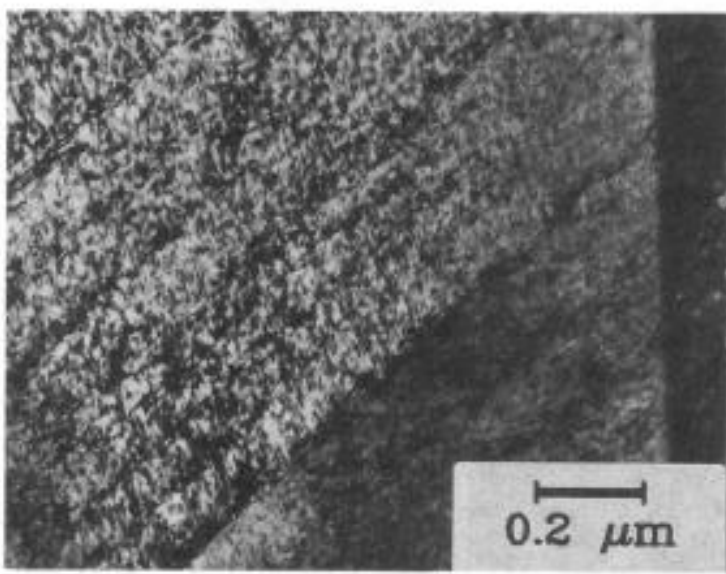

(a) Deformation with dislocation-dislocation interactions within the slip bands

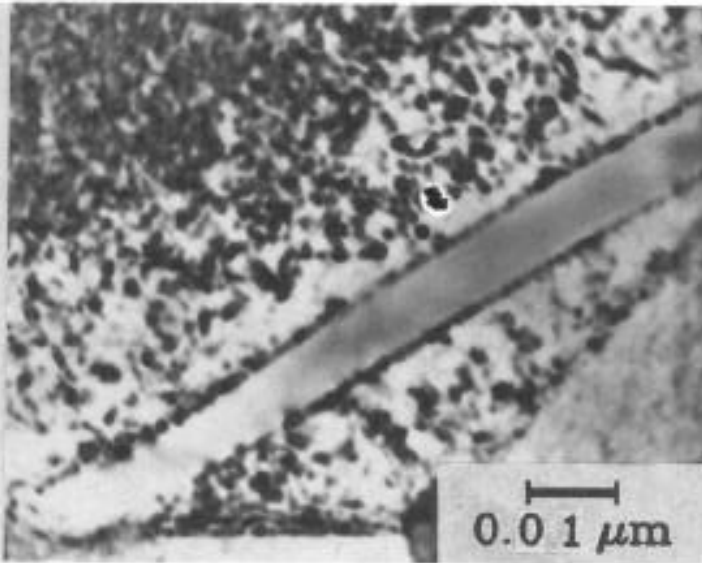

(b) Deformation band devoid of precipitates

Figure 7 - Substructure in Inconel 718 tested under a monotonic tensile strain of $2 \%$ followed by fatigue at a strain range of $2 \%$

deformation during fatigue in the specimen subjected to $10 \%$ tensile pre-strain is mostly confined to the deformation bands activated during monotonic straining. Heavy localization of deformation in planar slip bands and dislocation tangles within the deformation bands were observed (Figs. 8a, $8 \mathrm{~b}$ and $8 \mathrm{c}$ ). Occasional dislocation pairs and dislocation-dislocation interactions were noticed in between the well-defined slip bands in the matrix (Fig. 8d). The shearing of $\gamma^{\prime \prime}$ within the matrix could occur because of the extensive work hardening in the slip bands. It appears that the increased internal resistance due to dislocation tangling within the slip bands is much larger than the stress required for initiating the shearing of $\gamma^{\prime \prime}$ in the inter slip band regions.

The deformation even in the specimen tested under $10 \%$ monotonic tensile strain followed by fatigue at a strain range of $0.8 \%$ was confined mainly to the planar slip bands. Some dislocation tangling could be seen within the bands (Fig. 9). Homogeneous distribution of dislocations was noticed near some of the grain boundaries. However, at the lower strain range the matrix region between the slip bands was relatively free of dislocations. The $10 \%$ tensile pre-strain appears to have decreased the capacity for subsequent activation of additional slip bands during fatigue at the lower strain range of $0.8 \%$.

\section{Discussion}

Deformation in Inconel 718, was inhomogeneous and occurred along multiple planar arrays at room temperature. Under monotonic tensile strain the deformation bands showed evidence of dislocation-precipitation interaction. Presence of pairs of dislocations clearly indicated that the main strengthening precipitates, $\gamma^{\prime \prime}$, are sheared by glide dislocations $(5,6)$. Dislocations piled-up against the ordered precipitate increase the internal stress in the precipitate, until a dislocation passes through the precipitate. This disturbs the ordering of the precipitate and creates an 


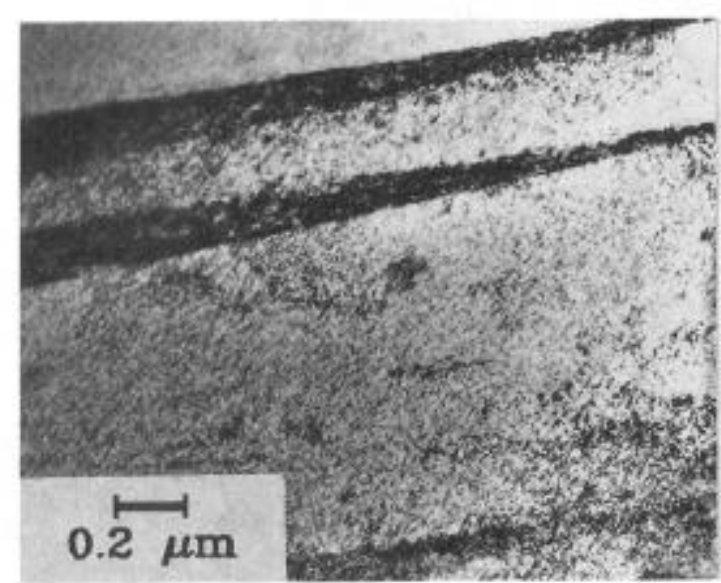

(a) Heavy localization of deformation in planar slip bands

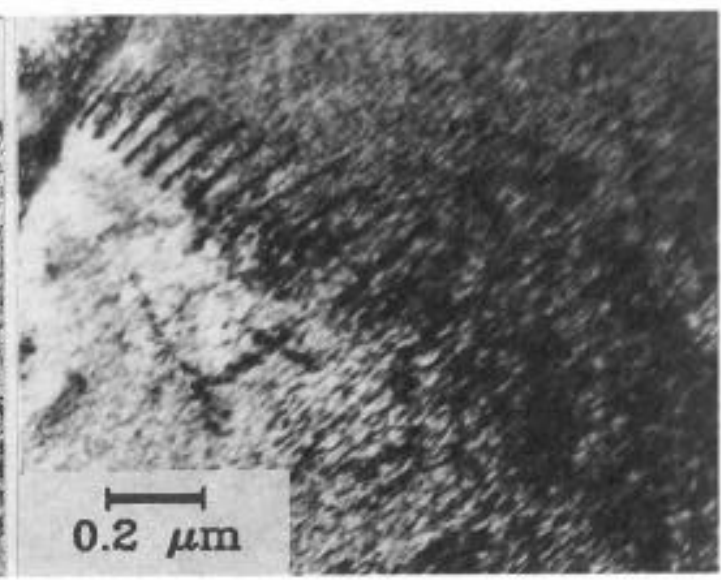

(b) Dislocation pile-up at a grain boundary

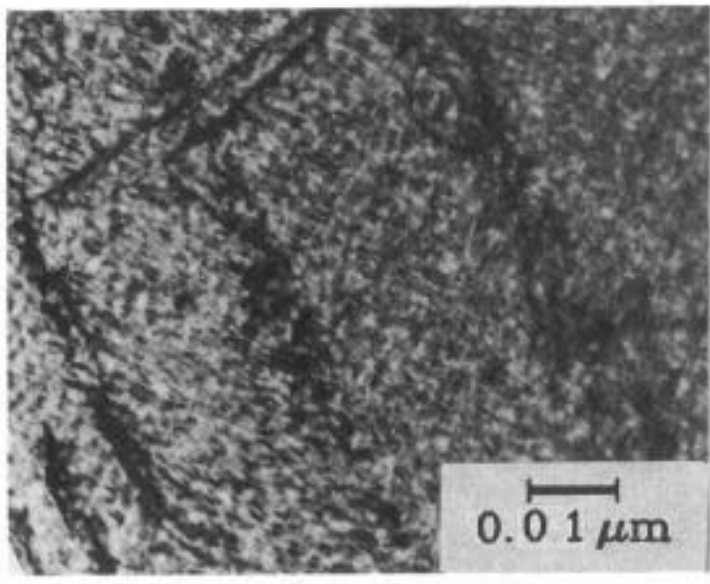

(c) Dislocation tangles within deformation bands

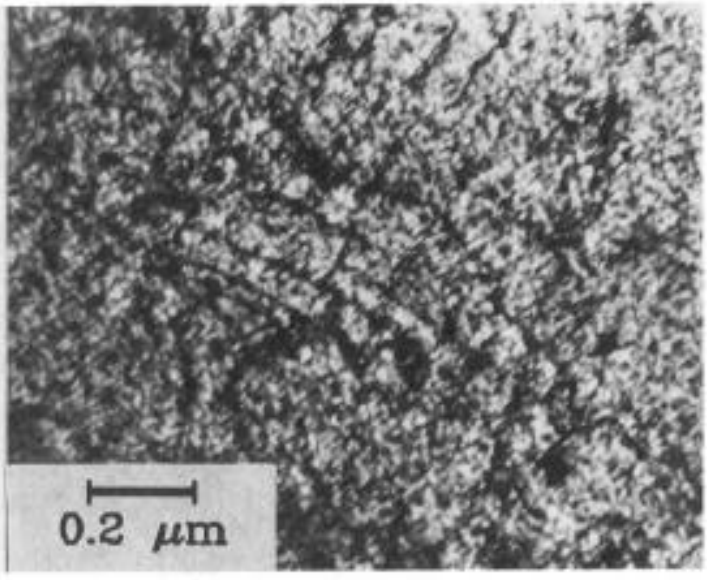

(d) Dislocation pairs and dislocation-dislocation interactions in the regions between the slip bands

Figure 8 - Substructure in Inconel 718 tested under a monotonic tensile strain of $10 \%$ followed by fatigue at a strain range of $2 \%$

antiphase boundary within the particle and raises the energy level of the system. Passage of a second dislocation through the precipitate restores the order and reduces the energy level $(6,15)$. Shearing of $\gamma^{\prime \prime}$ precipitates in slip bands, during the initial stages, sets up preferential paths for the movement of dislocations during the progressive deformation of the material.

Under fully-reversed fatigue, as the cycling continues, the strengthening $\gamma^{\prime \prime}$ precipitates present in slip bands seem to get sheared into separate halves by the leading dislocations. After this initial 


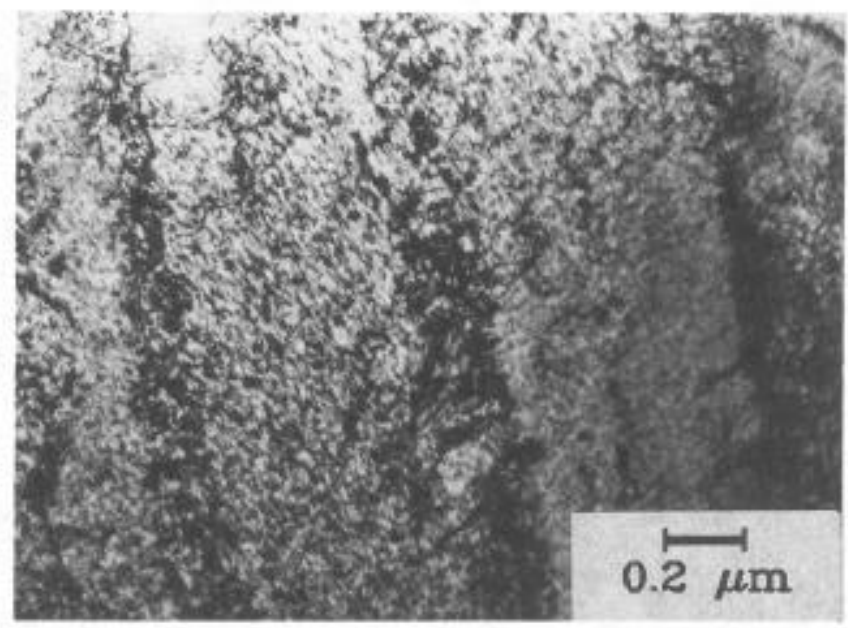

Figure 9 - Dislocation tangles within planar slip bands in Inconel 718 tested under a monotonic tensile strain of $10 \%$ followed by fatigue at a strain range of $0.8 \%$

splitting of $\gamma^{\prime \prime}$, the trailing dislocations in the same slip plane would repeatedly shear the $\gamma^{\prime \prime}$ precipitates and continuously reduce their size to an extent that they offer very little or no resistance to the movement of dislocations. This phenomenon causes cyclic softening and leads to apparently precipitate-free deformation bands. Such bands were observed in Inconel 718 by Merrick (10) and Worthem et al. (12). Fournier and Pineau (11), who also observed similar bands in Inconel 718 , believed that the deformation bands are only apparently denuded of the precipitates and attributed cyclic softening to the reduction of the mean size of the precipitates and an alteration in the original stacking sequence of $\gamma^{\prime \prime}$ precipitates, unlike Merrick (10), who attributed it to mechanical dissolution of precipitates. The mechanical destruction of the precipitates and associated reduction in their size is a highly viable explanation for cyclic softening. Shearing of precipitates was reported as the primary mechanism for softening in other superalloys such as Waspaloy and Nimonic $80 \mathrm{~A}$ (15), which also contain small volume fraction of precipitates as in the case of Inconel 718. Fournier and Pineau (11) identified the deformation bands as twins in Inconel 718 . In the present study, microtwinning was observed mainly in the higher $(2 \%)$ strain range fatigue test whereas slip bands were observed at both strain ranges.

The lower stress range observed in the $0.8 \%$ strain range fatigue test on a specimen pre-strained to $10 \%$ tensile strain (Figs. 3 and 4 ) is due to the damage caused to the $\gamma^{\prime \prime}$ precipitates along a few well-defined slip bands during the pre-strain. Subsequent deformation during fatigue was confined to these well-defined slip bands, which permitted movement of dislocations with lower resistance, and thus lowering the stresses necessary to achieve the required strain range. The tensile pre-strain of $10 \%$, reduced the fatigue life of the alloy at the lower strain range $(0.8 \%)$ by nearly a factor of 5 . The observed life reduction could be due to two separate mechanisms. Concentration of slip in a few bands within the bulk of the material makes deformation very inhomogeneous and increases stress concentration at the intersections of slip bands and grain boundaries, which can serve as potential micro crack initiation sites. Since in a material deformed under monotonic tensile strain, it takes fewer cycles to pile-up dislocations at potential crack initiation sites, fatigue life of the deformed material is reduced compared to the as-received material. In addition, it might be expected that on the sample surface, deformation bands induced during tensile pre-strain would create microscopic steps, which are known to act as crack initiation sites (16). As a result, the crack initiation phase will be shortened with an associated reduction 
in overall fatigue life, particularly at the low strain ranges where the crack initiation phase constitutes a major portion of fatigue life.

\section{Conclusions}

The mechanisms of deformation and damage at room temperature in commercially heat-treated Inconel 718 were investigated under monotonic tensile deformation, fully-reversed fatigue, and monotonic tensile deformation followed by fatigue. The following conclusions are drawn from the present study.

1) At room temperature, deformation in Inconel 718 under monotonic tensile strain and fatigue occurred by co-planar slip. Dislocation pairs observed in the slip bands indicated that ordered $\gamma^{\prime \prime}$ precipitates were sheared during the deformation process.

2) In fatigue, at a strain range of $0.8 \%$, deformation occurred mainly by co-planar slip. At $2 \%$ strain range, in addition to co-planar slip some microtwinning was observed.

3) Cyclic softening observed during fatigue is attributed to the continuous "mechanical scrambling" of $\gamma^{\prime \prime}$ precipitates by dislocations in deformation bands, which eventually lead to the formation of precipitate-free deformation bands.

4) In specimens that were monotonically strained in tension followed by fatigue testing, deformation during the fatigue part of the test occurred mostly along the deformation bands activated during the monotonic tensile strain. In the test where the monotonic tensile strain is much larger than the subsequent fatigue strain range, the cyclic stress range observed during test was lower than that observed in the test without any pre-strain. This reduction in stress range is due to the channelization of deformation along the slip bands in which dislocation-precipitate interactions reduced the size of $\gamma^{\prime \prime}$ precipitates in the slip bands during the tensile pre-strain.

5) At a given strain range, the observed reduction in the fatigue lives of specimens that were monotonically pre-strained in tension compared to fully-reversed fatigue tests on specimens with no pre-stains is attributed to the ease with which dislocations can move along the deformation bands (activated during monotonic tensile strain) and pile-up at grain boundaries, which eventually makes the material susceptible to fatigue crack initiation at the grain boundaries. Microscopic steps induced on the specimen's surface by the tensile pre-strain might also contribute to the reduction in life by shortening the crack initiation phase of the overall fatigue life.

\section{$\underline{\text { Acknowledgements }}$}

K. Bhanu Sanakara Rao wishes to acknowledge National Research Council, Washington, DC for granting the associateship award. The diligent efforts of Mr. Chris Burke in the fatigue laboratory and the meticulous sample preparation for optical microscopy by Mr. Todd Leonhardt in the metallography laboratory at NASA Lewis Research Center are gratefully acknowledged.

\section{$\underline{\text { References }}$}

1. D. D. Krueger, "The Development of Direct Age 718 for Gas Turbine Engine Disk Applications," Superalloy 718 - Metallurgy and Applications, ed. E. A. Loria (Warrendale, PA: The Minerals, Metals \& Materials Society, 1989), 279-296.

2. A. H. Jones, "An Overview of Alloy 718 in Large Structural Castings," Superalloy 718 - 
Metallurgy and Applications, ed. E. A. Loria (Warrendale, PA: The Minerals, Metals \& Materials Society, 1989), 307-318.

3. R. P. Jewett and J. A. Halchak, "The Use of Alloy 718 in the Space Shuttle Main Engine," Superalloys 718, 625 and Various Derivatives, ed. E. A. Loria (Warrendale, PA: The Minerals, Metals \& Materials Society, 1991), 749-760.

4. D. F. Paulonis, J. M. Oblak, and D. S. Duvall, "Precipitation in Nickel-Base Alloy 718," Trans. ASM, 62 (1969), 611-622.

5. J. M. Oblak, D. F. Paulonis, and D. S. Duvall, "Coherency Strengthening in Ni Base Alloys Hardened by $\mathrm{DO}_{22} \gamma^{\prime \prime}$ Precipitates," Met. Trans, 5 (1974), 143-153.

6. M. C. Chaturvedi and Y. Han, "Strengthening Mechanisms in Inconel 718 Superalloy," Metal Science, 17 (1983), 145-149.

7. J. W. Brooks and P. J. Bridges, "Metallurgical Stability of Inconel Alloy 718," Superalloys 1988, ed. S. Reichman et al., (Warrendale, PA: The Metallurgical Society, 1988), 33-42.

8. J. F. Radavich, "The Physical Metallurgy of Cast and Wrought Alloy 718," Superalloy 718 Metallurgy and Applications, ed. E. A. Loria (Warrendale, PA: The Minerals, Metals \& Materials Society, 1989), 229-240.

9. A. Oradei-Basile and J. F. Radavich, "A Current T-T-T Diagram for Wrought Alloy 718," Superalloys 718, 625 and Various Derivatives, ed. E. A. Loria (Warrendale, PA: The Minerals, Metals \& Materials Society, 1991), 325-334.

10. H. F. Merrick, "The Low Cycle Fatigue of Three Wrought Nickel-Base Alloys," Met. Trans, 5 (1974), 891-897.

11. D. Fournier and A. Pineau, "Low Cycle Fatigue Behavior of Inconel 718 at $298 \mathrm{~K}$ and $823 \mathrm{~K}$," Met. Trans, 8A (1977), 1095-1105.

12. D. W. Worthem et al., "Cyclic Deformation and Damage Structure in Inconel 718," Biaxial and Multiaxial Fatigue, EGF 3, ed. M. W. Brown and K. J. Miller (London, UK: Mechanical Engineering Publications, 1989), 131-143.

13. G. F. Vandervoort and H. M. Jones,"Wrought Heat-Resistant Alloys," Metals Handbook, vol. 9, J. R. Davis et al. eds., (Metals Park, OH: American Society for Metals, 1985), 308.

14. J. L. Burger, R. R. Biederman, and W. H. Couts, "The Effects of Starting Condition on the Aging Response of As-Forged Alloy 718," Superalloy 718 - Metallurgy and Applications, ed. E. A. Loria (Warrendale, PA: The Minerals, Metals \& Materials Society, 1989), 207-217.

15. S. D. Antolovich and B. Lerch, "Cyclic Deformation, Fatigue and Fatigue Crack Propagation in Ni-base Alloys," Superalloys, Supercomposites and Superceramics, (Academic Press, Inc., 1989), 375 .

16. M. Gräf and E. Hornbogen, "The Effect of Inhomogeneity of Cyclic Strain on Initiation of Cracks," Scripta Metallurgica, 12 (2) (1978), 147-150. 